\title{
Propulsion Technology Lifecycle Operational Analysis
}

\author{
John W. Robinson ${ }^{1}$ \\ The Boeing Company, Huntington Beach, California, 92647 \\ Russel E. Rhodes ${ }^{2}$ \\ NASA, Kennedy Space Center, Florida, 32899
}

The paper presents the results of a focused effort performed by the members of the Space Propulsion Synergy Team (SPST) Functional Requirements Sub-team to develop propulsion data to support Advanced Technology Lifecycle Analysis System (ATLAS). This is a spreadsheet application to analyze the impact of technology decisions at a system-of-systems level. Results are summarized in an Excel workbook we call the Technology Tool Box (TTB). The TTB provides data for technology performance, operations, and programmatic parameters in the form of a library of technical information to support analysis tools and/or models. The lifecycle of technologies can be analyzed from this data and particularly useful for system operations involving long running missions. The propulsion technologies in this paper are listed against Chemical Rocket Engines in a Work Breakdown Structure (WBS) format.

The overall effort involved establishing four elements:

(1) A general purpose Functional System Breakdown Structure (FSBS).

(2) Operational Requirements for Rocket Engines.

(3) Technology Metric Values associated with Operating Systems

(4) Work Breakdown Structure (WBS) of Chemical Rocket Engines

The list of Chemical Rocket Engines identified in the WBS is by no means complete. It is planned to update the TTB with a more complete list of available Chemical Rocket Engines for United States (US) engines and add the Foreign rocket engines to the WBS which are available to NASA and the Aerospace Industry.

The Operational Technology Metric Values were derived by the SPST Sub-team in the form of the TTB and establishes a database for users to help evaluate and establish the technology level of each Chemical Rocket Engine in the database. The Technology Metric Values will serve as a guide to help determine which rocket engine to invest technology money in for future development.

\footnotetext{
${ }_{1}^{1}$ Principal Engineer/Scientist, Propulsion Engineering, 5301 Bolsa Avenue / H013-C313, AIAA Associate Fellow. ${ }^{2}$ AST, Technical Management, Engineering Directorate Design \& Development Eng Div Sys Engineering \& Integration Br, Kennedy Space Center, Florida/NE-D2, AIAA Senior Member.
} 


\section{Nomenclature}

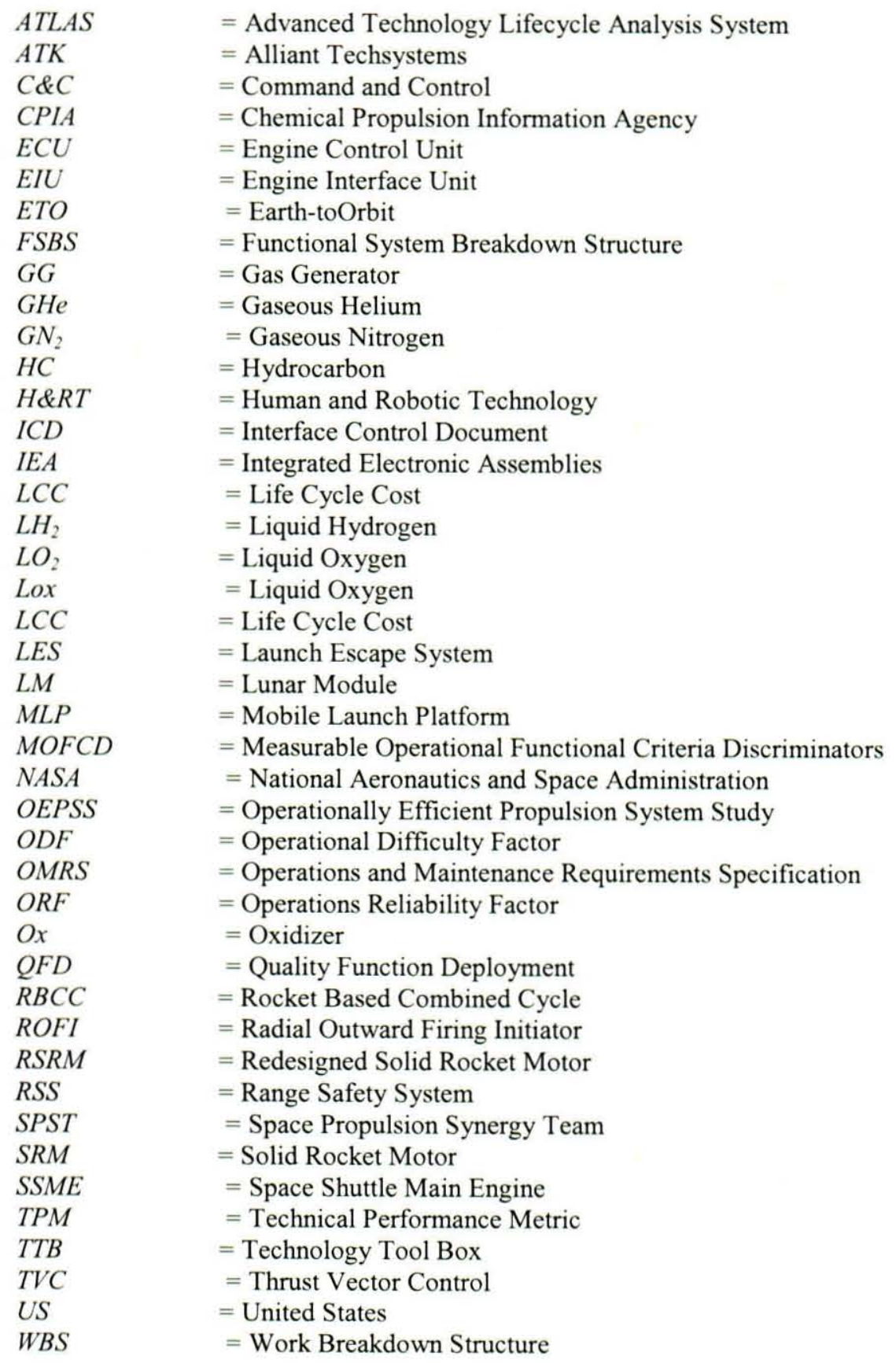

\section{Introduction}

In 2004 NASA was developing an "Advanced Technology Lifecycle Analysis System" (ATLAS), which was a spreadsheet application to analyze the impact of technology decisions at a system-of-systems level. At the heart of this ATLAS is an Excel workbook known as the "Technology Tool Box" (TTB). The TTB provides data for technology performance, operations, sand programmatic parameters used by models in the ATLAS library. As emphasized in the name, the models in ATLAS address the lifecycle of technologies. 
In support of the development of Operational Technologies and the development of Technology Metric Values for the ATLAS TTB, the SPST was requested to provide the development of Operational Metrics. In response to this request, the SPST developed the Operations Difficulty Factor (ODF) and an Operations Reliability Factor (ORF) for incorporation in the ATLAS TTB database for the first 3 year incremental time frame of 2005-2008 of an intended eleven time frames in the future through the year 2038.

To accomplish the development of these ODFs and ORFs, the SPST first identified Measurable Operational Functional Criteria Discriminators that could be used to develop the Operational Metric Values in the TTB. The process desired was to select a reference technology choice for each technology class and by comparing the technology choices against this reference considering a range of 1.0 to 10 . Thus, an order of magnitude from better to worse, setting the reference value at 1.0 and the range for better would be 0.1 to 1.0 and the range for worse would be 1.0 to 10 .

The TTB was conceived to support development of technologies starting with incremental time frames 2005-2008, 2008 - 2011, etc, for each of the technology options considering technology maturation advancement for each period.

The SPST worked two classes of Chemical Rocket Engines, WBS 2.6.1 Earth-to-Orbit (ETO) Propulsion Technology sub-element and WBS 2.6.5 In-space Propulsion (chemical/thermal) Technical sub-element.

The Operational Technology Metric Values derived by the SPST would be used by the ATLAS database users and modelers to help evaluate and establish the technology level of each Chemical Rocket Engine in the database. The Technology Metric Values were included in a Technology Investment Portfolio to serve as a guide to determine which technology would gain the greatest operational improvement for out year investments.

Methodology

The process selected by the SPST considered 16 different propulsion system in the ETO class (WBS 2.6.1) and 13 different propulsion systems in the In-space class (WBS 2.6.5) for evaluation. Some of these propulsion systems were well established operational systems and others were either less mature or notional systems. The SPST had performed a QFD in previous studies that had identified many design discriminators against the desired attributes for an affordable/sustainable space transportation system. These design discriminators were arranged in an order of importance and the top applicable Measurable Operational Functional Criteria Discriminators (MOFCD) were used to perform the evaluation of the selected propulsion systems to determine their ODF and used to perform the evaluation of these propulsion systems ORF.

One additional criterion was added that determined the maturity (a well documented operational definition of discriminator data) for evaluation and understanding. This criteria was evaluated on the basis of a 1 (well defined), 3 (somewhat defined), and a 9 (not well defined at all). This added criterion would add a burden to those systems that were not mature, but could be removed when these technologies were developed and demonstrated as being mature. This 
allows for selection of future systems for development that show promise in reaching the objective of being more affordable than the present system being used today. Future time frame evaluations would take into account the advances made to mature technology propulsion systems. At this time frame the criterion that was added for the evaluation of this maturity would be reduced; therefore, the raw score for that technology would be reduced from the previous time frame yielding a lower ODF and a new ORF.

It was found that only 28 criteria were evaluated out of a larger group as data was missing in the others which were evaluated with a score of 0 or left blank. This evaluation was performed using a matrix that allowed the evaluation of each propulsion system against each Measurable Operational Functional Criteria Discriminators with the SSME being selected as the reference case for the ETO class and the RL-10 A-4 selected as the reference case for the In-space class. Each propulsion system was evaluated and the scores were added to determine the raw score of each. Each raw score was then normalized against the reference case, e.g., the ODF and ORF and transferred to the ATLAS TTB.

\section{Operational Analysis Results (grouped in three categories)}

(1) A general purpose Functional System Breakdown Structure (FSBS).

(2) Work Breakdown Structure (WBS) of Chemical Rocket Engines

(3) Technology Metric Values associated with Operating Systems

\section{General Purpose Functional System Breakdown Structure (FSBS):}

This generic FSBS (a product of a previous study effort that was discontinued) was requested by our customer as a part of this task. The generic FSBS was developed to provide the capability to analyze technologies within the existing TTB, and would also reflect the Advanced Systems Technology Research and Analysis WBS.

To develop a generic FSBS applicable to all phases and missions of a Space Transportation System, the SPST Sub-team reviewed past Space Transportation Systems and their WBSs, many of which have been used for 50 plus years. A generic FSBS was developed that is applicable to any Space Transportation System (flight system, ground system and ground functional nodes in space or on other planets).

\section{Work Breakdown Structure (WBS) of Chemical Rocket Engines}

Operational Discriminators and the development of Technology Metric Values for Technologies were defined by reviewing the Chemical Rocket Engines within the ATLAS data base to determine their technology levels for potential Development Technologies to be included in the Human and Robotic Technology (H\&RT)'s technology Investment Portfolio. The H\&RT requested the SPST Functional Requirements Sub-team to develop the Operational Metrics for the ATLAS TTB. When reviewing the Chemical Rocket Engines in the existing WBS, it became obvious that the list of available Chemical Rocket Engines, both United States (US) and foreign needed to be up-dated to provide a complete-as-possible listing of Chemical Rocket Engines that are or could be available to NASA and the Aerospace Industry. 
The WBS 2.6.1 for ETO rocket engines lists thirteen rocket engines, two rocket motors and one propulsion technology. Seven are qualified Liquid Rocket Engines, but only five are still flying; the SSME, RS68, RS27A from the US, the HM 60 from France, and the RD180 from Russia. There are two qualified Solid Rocket Motors' the Apollo LES (retired) and the RSRM still flying both from the US. The RD170 was in the WBS listing, but is no longer in production; therefore, the SPST Sub-team replaced it with the RD173 ETO technology engine, and is identified by a 3 in the fifth digit of the WBS as shown in Table 1.0 below.

\section{WBS 2.6.1 -- ETO Propulsion}

$\begin{array}{ll}\text { WBS 2.6.1.1.2 - SSME - Reference Engine } & \text { US } \\ \text { WBS 2.6.1.1.1 - RS68 - Qualified Engine } & \text { US } \\ \text { WBS 2.6.1.1.3 - HM60 - Qualified Engine } & \text { France } \\ \text { WBS 2.6.1.1.4 - F-1 - Retired Engine } & \text { US } \\ \text { WBS 2.6.1.1.5 - J-2 - Retired Engine } & \text { US } \\ \text { WBS 2.6.1.3.1 - RBCC - Technology Engine } & \text { US } \\ \text { WBS 2.6.1.3.2 - Linear Aerospike Technology Engine } & \text { US } \\ \text { WBS 2.6.1.3.3 - Annular Aerospike Technology Engine } & \text { US } \\ \text { WBS 2.6.1.5.1 - Solid/Hybrid - Technology Engine } & \text { US } \\ \text { WBS 2.6.1.5.2 - RSRM - Qualified Propulsion } & \text { US } \\ \text { WBS 2.6.1.5.3 - Apollo LES Retired Propulsion } & \text { US } \\ \text { WBS 2.6.1.6.1 - RS72 - Technology Engine } & \text { US/German } \\ \text { WBS 2.6.1.6.2 - RS27A - Qualified Engine } & \text { US } \\ \text { WBS 2.6.1.6.3 - RD173 - Technology Engine } & \text { Russia } \\ \text { WBS 2.6.1.6.4 - RD180 - Qualified Engine } & \text { Russia } \\ \text { WBS 2.6.1.8.1 - MGLV - Concept Technology Propulsion } & \text { US }\end{array}$

Table 1.0 - WBS 2.6.1 ETO Engines/Propulsion evaluated by the SPST Sub-Team

WBS 2.6.5 for In-space rocket engines identifies eleven rocket engines, one rocket motor and one propulsion technology. Five are qualified Liquid Rocket Engines, but only one is still flying; the RL10A-4. The Chemical Propulsion Information Agency's (CPIA) rocket engine database shows the RL10A-4 and not the RL10A-6 as a viable rocket engine. Therefore, the RL10A-6 was replaced with the RL10A-4 engine in the database. The Solid/Hybrid technology motor was added to the WBS. The RS27A derivative technology engine was added in place of the "Noname LOX/HC" engine. The MB60, the RL60, the Apollo LM Descent, the RS72, the Solid/Hybrid, the OEPSS Concept, and the MGLV Concept Technologies were added and identified by an $\mathrm{X}$ in the fifth digit of the WBS number as shown in Table 2.0 below. 
WBS 2.6.5.1.1 - RL10A-4 - Reference Engine US

WBS 2.6.5.1.X - MB60 -Technology Engine US

WBS 2.6.5.1.X - RL60 - Technology Engine US

WBS 2.6.5.1.2 - HM60 Derivative - Technology Engine France

WBS 2.6.5.1.3 - J-2 Retired Engine US

WBS 2.6.5.1.5 - Apollo CSM SPS - Retired Engine US

WBS 2.6.5.1.6 - Apollo LM Ascent - Retired Engine US

WBS 2.6.5.1.X - Apollo LM Descent - Retired Engine US

WBS 2.6.5.2.1 - RS27A Derivative - Technology Engine US

WBS 2.6.5.8.X - RS72 - Technology Engine US/German

WBS 2.6.5.8.X - Solid/Hybrid - Technology Motor US

WBS 2.6.5.X.X - OEPSS Concept - Technology Engine US

WBS 2.6.5.X.X - MGLV Concept Technology Propulsion US

Table 2.0 - WBS 2.6.5 In-space Engines evaluated by the SPST Sub-Team

The SPST Sub-team selected the SSME as the reference ETO engine and all technology ETO propulsion systems were compared to the SSME. For the In-space rocket engines, the RL10A-4 was selected as the reference engine and all In-space technology propulsion systems were compared to the RL10A-4.

\section{(3) Technology Metric Values associated with Operating Systems}

In defining a process that could work with multiple objective attributes, the SPST performed a QFD exercise. This process was accomplished in previous studies that had identified the many design drivers that were responsive to the attributes of an affordable / sustainable space transportation system. These design drivers are sometimes referred to as "technical performance metrics" (TPMs); however, in this paper they will be referred to as "operational functional criteria discriminators". These operational design discriminators were arranged in an order of importance and the top applicable 48 measurable operational functional criteria discriminators were used to perform the evaluation of the selected propulsion systems to determine their ODF and the top applicable 48 measurable operational functional criteria discriminators were used to perform the evaluation of these propulsion systems ORF.

Forty-eight Operational Discriminators were used to evaluate the one reference engine and the all the other engines/propulsion systems in the WBS 2.6.1 ETO Propulsion shown in Table 1.0 above. Establishing the SSME as the reference ETO engine with a nominal value of 1.0, and comparing the technology and other engines/propulsion systems on a scale of 0.1 to 10 ; with 0.1 being an order-of-magnitude better and 10 being an order-of-magnitude worse than the SSME, provided the SPST Sub-team with a structured methodology and technique to derive Technology Metric Values for each Operational Discriminator for each rocket engine/propulsion concept evaluated.

Forty-eight Operational Discriminators were also used to evaluate the one reference engine and all the other engines/propulsion systems in the WBS 2.6.5 In-space Propulsion shown in Table 2.0 above. Establishing the RL10A-4 as the reference In-space engine with a nominal value of 1.0, and comparing the technology and other engines/propulsion systems on a scale of 
0.1 to 10 ; with 0.1 being an order-of-magnitude better and 10 being an order-of-magnitude worse than the RL10A-4, provided the SPST Sub-team with a structured methodology and technique to derive the Technology Metric Values for each Operational Discriminator for each engine evaluated concept evaluated.

Because there wasn't data for all the 48 measurable operational functional criteria discriminators, only 28 criteria are presented in this technical paper as being used to evaluate the propulsion technologies for both the ETO and the In-Space WBS groups. For definition of the 28 measurable operational functional criteria discriminators use, please see the "evaluation products examples" that follow.

One additional criterion was added that determined the maturity (well documented operational definition of these discriminator data) for evaluation and understanding. This criteria was evaluated on the basis of a 1 (well defined), 3 (somewhat defined), and a 9 (not well defined at all). This added criterion would add a burden to those systems that were not mature, but could be removed when these technologies were developed and demonstrated as being mature. This allows for selection of future systems for development that show promise in reaching the objective of being more affordable that the present system being used today. Future time frame evaluations would take into account the advances made to mature technology propulsion systems. At this time frame the criterion that was added for the evaluation of this maturity would be reduced; therefore, the raw score for that technology would be reduced from the previous time frame yielding a lower ODF and a new ORF.

\section{Evaluation Product Examples}

The SPST only preformed the first year 2005 evaluation for these selected systems. In addition to evaluating the gains from maturing an advanced design, it can be seen that if a mission requires large thrust values the ODF must be compared with multiples of smaller propulsion systems. Therefore, from a total systems perspective even though the ODF is larger than that of another system, it may be the desired choice.

The following three examples for ETO (WBS 2.6.1) show that with all systems being mature, the SRM has much higher thrust than the other two cases; therefore, if it was replace with another choice, it needs to be relatively close to the SRM's thrust level. The ODF and ORF would not be desirable for the reference system if it required 5-6 units to match the desired required equivalent thrust.

These example propulsion system evaluations make it clear which Operational Discriminators are candidates for improvement if it is desired to improve the operability of any of these mature technologies. 


\begin{tabular}{|c|c|c|c|c|c|c|c|c|c|}
\hline Criteria Discriminators & $\begin{array}{c}\text { Ref Technology } \\
\text { (SSME) LO } \mathrm{O}_{2} / \mathrm{LH}_{2} \quad 2.6 .1 .1 .2 \\
\text { (Operational Rocketdyne Engine) }\end{array}$ & Value & $\begin{array}{l}\text { Criteria } \\
\text { Factor }\end{array}$ & $\begin{array}{c}\text { RS } 68 \mathrm{LO}_{2} / \mathrm{LH}_{2} \text { 2.6.1.1.1 (Operational } \\
\text { Rocketdyne Engine) }\end{array}$ & Value & $\begin{array}{l}\text { Criteria } \\
\text { Factor }\end{array}$ & $\begin{array}{l}\text { Shuttle SRM Solid 2.6.1.5.2 } \\
\text { (Operational ATK Motor) }\end{array}$ & Value & $\begin{array}{l}\text { Criteria } \\
\text { Factor }\end{array}$ \\
\hline 1. Closed Compartments/Confined & Not Rocket Engine Focused & N/A & & Not Rocket Engine Focused & N/A & & Not Rocket Engine Focused & N/A & \\
\hline $\begin{array}{l}\text { 2. Number of Different Operating } \\
\text { Fluids Serviced: }\end{array}$ & $\mathrm{LH}_{2}, \mathrm{LO}_{2}, \mathrm{GN}_{2}, \mathrm{GHe}, 83282$ Hydraulic Oil & 5 & 1 & $\mathrm{LH}_{2}, \mathrm{LO}_{2}, \mathrm{GHe}, 83282$ Hydraulic Oil & 4 & 0.8 & GN2 & 1 & 0.2 \\
\hline $\begin{array}{l}\text { 3. Number of Ground Servicing } \\
\text { Interfaces: }\end{array}$ & $\begin{array}{c}5 \text { Post-flight } \mathrm{GN}_{2} \text { drying purges \& } 2 \text { Pre- } \\
\text { flight } \mathrm{GHe}, \text { Heated } \mathrm{GN}_{2} \text { conditioning } \\
\text { purges }\end{array}$ & 7 & 1 & GHe spin start \& GHe purges & 2 & 0.29 & $\begin{array}{c}T-0 \text { umbillical at the MLPIAft to provide } \\
\text { joint heater power/temperature } \\
\text { control \& aft skirt heated purge to } \\
\text { provide flex joint temp control. }\end{array}$ & 2 & 0.29 \\
\hline $\begin{array}{l}\text { 4. Total Number of Tanks in the } \\
\text { Architecture: }\end{array}$ & $\begin{array}{l}10 \mathrm{GHe} \text { Bottles, } 4 \text { Hydraulic } \\
\text { Containers, LH2 \& LO2 Tanks }\end{array}$ & 16 & 1 & $\begin{array}{l}\text { Lox \& LH2 tanks, } 5 \pi \text { He bottles that } \\
\text { are thrust dependent (Heavy @ } 7 \text { ) }\end{array}$ & 9 & 0.56 & $\begin{array}{l}1 \text { pressure vessel with } 4 \text { RSRM } \\
\text { segments with } 7 \text { joints }\end{array}$ & 1 & 0.1 \\
\hline $\begin{array}{l}\text { 5. Total Number of Vehicle } \\
\text { Support Systems: }\end{array}$ & $\begin{array}{l}\text { LH2 tank \& feed-system, LO2 tank \& } \\
\text { feed-system, He pneumatic supply sys, } \\
\text { Heated GN2 purge sys, Lox anti- } \\
\text { geysering sys, GO2 tank } \\
\text { pressurization sys, GH2 tank } \\
\text { pressurization sys, POGO suppression } \\
\text { sys, Two hydraulic supply sys, LH2 } \\
\text { recirculation conditioning sys, LO2 } \\
\text { bleed conditioning sys, TVC sys, Four } \\
\text { TVC controllers, Two } 28 v 0 \text { olt power } \\
\text { supply sys, Two } 400 \text { cycle AC power } \\
\text { supply sys, Three Vehicle C\&C (EIU) } \\
\text { sys, Instrumentation interface sys, \& } \\
\text { TPS heat shield }\end{array}$ & 26 & 1 & $\begin{array}{l}\text { LH2 tank \& feed-system, LO2 tank \& } \\
\text { feed-system, He pneumatic supply } \\
\text { sys, Lox anti-geysering sys, GO2 tank } \\
\text { pressurization sys, GH2 tank } \\
\text { pressurization sys, POGO } \\
\text { suppression sys, hydraulic supply } \\
\text { sys, LH2 bleed conditioning sys, LO2 } \\
\text { bleed conditioning sys, } 3 \text { TVC sys, } \\
\text { TVC controllers, Two } 28 v \text { volt power } \\
\text { supply sys, Two 400cycle AC power } \\
\text { supply sys, Instrumentation interface } \\
\text { sys, \& TPS heat shield }\end{array}$ & 24 & 0.92 & $\begin{array}{l}\text { Range Safety Sys, Pyrotechnic nozzle } \\
\text { separation sys, } 2 \text { lgnition Firing Sys, } \\
\text { TVC sys, Four TVC controllers, Two } \\
\text { 28volt power supply sys, } \\
\text { instrumentation interface sys, Two } \\
\text { Integrated Electronic Assemblies (IEA) }\end{array}$ & 14 & 0.54 \\
\hline $\begin{array}{l}\text { 6. Total Number of Ground } \\
\text { Interface Functions Required: }\end{array}$ & $\begin{array}{l}\text { Source is the Design Ref.Doc. ICD's, } \\
\text { e.g., test ports, nozzle covers, } \\
\text { inspection interface points. }\end{array}$ & 25 & 1 & $\begin{array}{l}\text { Source is the Design Ref.Doc. ICD's, } \\
\text { including nozzle, } 2 \text { exhaust and } 5 \\
\text { drain line covers, } 2 \text { TP inspection } \\
\text { ports, } 2 \text { GG pyro igniters, ROFI }\end{array}$ & 13 & 0.52 & $\begin{array}{l}\text { Source is the Design Ref.Doc. ICD's } \\
\text { leak test ports (12), joint heaters - } \\
\text { power \& monitoring (9) }\end{array}$ & 21 & 0.84 \\
\hline $\begin{array}{l}\text { 7. Total Number of Separate } \\
\text { Identified Vehicle Systems (lack of } \\
\text { discipline functional integration): }\end{array}$ & Not Rocket Engine Focused & N/A & 1 & Not Rocket Engine Focused & N/A & & Not Rocket Motor Focused & N/A & \\
\hline $\begin{array}{l}\text { 8. Number of Separate } \\
\text { ElectricaVElectronic Interfaces: }\end{array}$ & Please see electrical listing in item \#9 & 12 & 1 & $\begin{array}{l}\text { 2 GG pyro igniters, ancillary valves } \\
\text { switch position, TVC1/Roll Control } \\
\text { Nozzle primary and complementary, } \\
\text { TVC2 primary and complementary, } 2 \\
\text { power supply channels to ECU, } 6 \\
\text { instrumentation, ROFI for main } \\
\text { combustion chamber }\end{array}$ & 16 & 1.33 & Please see electrical listing in item \#9 & & 1.91 \\
\hline
\end{tabular}


(12) Mech \& (12) Ele: $\mathrm{LH}_{2} \& \mathrm{LO}_{2}$ feedlines, $\mathrm{GH}_{2} \& \mathrm{GO}_{2}$ presslines, $\mathrm{GHe}$ \& $\mathrm{GN}_{2}$ Supply lines, Hydraulic Supply \&

9. Number of Mechanical Element Mating Operations:

Return lines, LH2 Conditionin Bleedline, Gimbleblock \& (2) TVC Actuators and (2)AC \& (2)DC power, (2) Command/Data, a Command only,

$$
\text { main fuel valve heater \& (4) }
$$

Instrumentation Electrical Connectors

10. Number of Safing Operations at Landing:

High pressure bottles must be vented to $50 \%$ level before personnel exposure.

11. Number of Safety Driven Limited Access Control

Operations:

12. Number of Commodities used that Require Medical Support Operations or Routine Training:

Working with inert gases, in confined spaces, and with cryogenics requires special training.

Main fuel valve, Main Lox valve, $\mathrm{Ox}$ Preburner lox supply valve, Fuel preburner lox supply valve, Heated GN2 purge valve, Lox dome purge valve, Fuel coolant supply valve, Fue coolant system He purge valve, High

13. Total Number of Active pressure lox turbopump, Low pressure Components:

lox turbopump, High pressure fuel

turbopump, Low pressure fuel

turbopump, Pneu shutdown supply

valve, Flow meter, Six augmented POGO \& five propellant valve solenoids and five check valves
(16) ele \& (22) mech: pump inlets, ox bleed, ox dome purge, Inter Propellan Seal (IPS), ox \& fuel tank pressurants, GG fuel purge, fuel sys purge, $G G$ ox purge, 2 TVC hydraulic supply \& return, bleed valve actuation, fuel bleed, Fuel Bleed-Drain/Diverter Valve, barrier purge, 4 structural attach points, spin start, hydraulic turbine exhaust

Safe the GG igniter sys \& vent high pressure bottles to $50 \%$ level

Engine Handling, Inert Purging, Pressurizing to Flight Values, \& ROFI installation

Working with inert gases, in confined spaces, and with cryogenics requires special training.

Fuel pump, LOX pump, 4 main valves, 3 bleed valves, 1 FDDV, 9 check valves, \& 3 TVC actuators
(18) Mech \& (23) Ele: (4) Motor segment mating, (3) Leak check segment/segment joints, mating to aft Skirt, mating to nozzle, leak check nozzle joint, mate S\&A Leak Check (3) aft structural struts to $E T$, mate forward structural attachment to ET, attach (2) TVC actuators, install electrical tunnel, mate (2) electrical cables to igniters, mate electrical cables to instrumentation mate ectricalcables to safo \& for Racterice for Range Safety sys, (2) TVC actuator ele connections, (8) ele. connectors to joint heaters and to ground interface per motor, (8) ele. connectors to joint heater instrumentation and to ground interface per motor

Safe the ignition sys, inspect the pyrotechnic nozzle separation sys, safe the range safety sys, remove and

$$
\text { dispose RSS }
$$

(5) motor major componen inspections and handling, (7) structural element mating operations/motor, installation of ignition Safe \& Arm Device, installation of range safety ordnance, ordnance electrical connections

All Solid Rocket handling operations, all ordnance device handling operations, with inert gases

Flex nozzle, Safe \& Arm device for motor ignition, and Safe, nozzle 0.67 separation sys \& Safe, Arm device for the Range Safety sys, and (2) TVC gimbal actuators 
14. Number of Safety Driven

Safety Functional Requirements to Maintain Safe Control of System during Flight and Ground Operations:

15. Number of Critical - 1 (Crit-1)

System Functional Failure

$$
\text { Modes: }
$$

16. Number of Intrusive Data Gathering Devices:

17. Number of Maintenance Actions Planned Between Missions:

18. Number of Maintenance Actions Unplanned Between Missions:

19. Expected Operational Lifetime Firings:

20. Expected Reusability-Number

\section{Expected Reusability (\% HM} Replaced per Firing): (PRACA) \& Plannin and Scheduling Sys (CAPSS) As-ru

22. Expected Operational Lifetime - Source is the Design Ref.Doc. Of Hours:

Operations and Maintenance Requirements Specification (OMRS) presure suppression, ignition overshutdown, ignition, pneumatic shutdown \& Lox turbopump seal

$$
\text { 9/28/2004 }
$$

Temperature, 19 Pressure, 1 Flow.

and fuel bleed valve sensors, \& 6

Source is the Design Ref.Doc. O s and Maintenance and Scheduling Sys (CAPSS) As-run

Source is the Design Ref.Doc. O Operations and Maintenance

ource is the Design Ref.Doc. Of Operations and Maintenance Requirements Specification (OMRS)
Haz gas system, engine cryo conditioning, IPS purge, barrie (Lox \&

is the Design Ref. For Crit 1 \& $\quad 550 \mathrm{Crt} 1$ \& $1 \mathrm{R}$ with

$313 \mathrm{Crt} 1 \& 237 \mathrm{Crt}$

$1 \mathrm{R}$ per engine

rate, Lox anti-flood valve sensor, 5

propellant flow control valves sensors,

Source is the Problem Reporting and Corrective Action (PRACA) \& Planning

0 starts $/ 15,000$

N/A

N/A

N/A

(Salvage \& reuse) Must recover from ocean, rough clean motor, dissemble,

return to manufacture for reload, and totally rebuild both at manufacture HG-AF, ARF and launch site for next flight -132 tasks \& MLP 164 tasks

Varies between missions, but it is suggested some rework of assembly of motor

Designed for 20 flights, but

8 starts $\quad$ splashdown loads vary from flight to

I 1,200 3.75 flight causing a periodic loss of aft segment

Complete Refurb each flight (starts)@122 sec each

Expendable engine; however,

certification was for 12 starts and 1800 TBD $\mathrm{sec}$

N/A

N/A

less than $1 \%$

BD

Major components are reusable, small parts/ non-configured items are

$$
\text { typically not }
$$

The intended reusable aspect of the motor is 20 flights @ 122 sec each

and 20 ints

hardware. Flight data suggests that less than 1 hour hardware. Flight data suggests that
major flight components, case cyl, aft skirt, stiff rings have less than designed life due to splashdown loads.

64


Design Assessment

23. Mean Time Between Failure (MTBF):

24. Minimize the Number of

Hazardous Fin Used:

25. Avoid the Use of Toxic Fluids Cleaning solvents, but not considered and Materials:

6. Provide Propulsive Sys. Tha Ra Large Thrus Range:

27. Provide Propulsive Sys. That Accomodate a Large Impulse Control Range with focus on the Minimum Impluse Side:

28. Provide Automated Hardware Corrective Action Capability:

29. Provided well documented data

Notes or Normalized value for this technology option (These values are for Criteria 29 influence on Criteria Factor on(y)

AD JUSTED: Normalized value for this technology option (These on Criteria Factor on(y)
Source is: MSFC S\&MA Concept Study Support

July 21, 2004

benign failure

with SSME Rel of

9987 (.999974

Catastrophic)

Cleaning solvents, but No special protective garments required$$
\text { toxic }
$$

Thrust range is 65 to $109 \%$

1

Not determined
2 Igniters and 1 ROFI ordnance
devices
None
Two fixed points of operation, e.g.,
throttle prior to MECCO and G level
control

Not ETO Rocket Engine Focused

Automated SSME shutdown

HPOT IMSL Purge below 170 PSIA MCC Pressure (differntial) is greater than 200 PSIA from Pc (Calculated) Reference \& 400 PSIA during throttling HPOT Discharge Temp above $1760^{\circ}$ HPFT Discharge Temp above $1960^{\circ}$ Prior to T-0 (Confidence Confirmed) HPFP Shaft Speed less than 4600 RPM
. MCC Pressure below 290 PSIA MCC Pressure not between 610 1000 PSIA

than $80 \%$

Fuel Preburner S/D Purge Pressure PSIA later in start

- Oxidizer Preburner S/D Purge

Pressure sensor 100 PSIA later in start
abovis

$\begin{array}{ccc}0 & 1 & \begin{array}{c}2 \text { Igniters and } 1 \text { ROFI ordnance } \\ \text { devices }\end{array} \\ 0 & 1 & \text { None } \\ \begin{array}{c}109 \%=44 \% \\ \text { range }\end{array} & 1 & \begin{array}{c}\text { Two fixed points of operation, e.g., } \\ \text { throttle prior to MECO and } \mathrm{G} \text { level } \\ \text { control }\end{array}\end{array}$

N/A

Not ETO Rocket Engine Focused

No in-flight redlines; Prior to T-0: MFV position indication $>6.5 \%, G G$ link confirmed, FTPIOTP discharge

10 pressures $>204 / 192$ psia, turbine inlet temp 875-1075F, MOV position 81-88\%

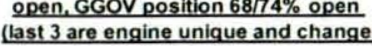
slightly for each engine)
Design Source is: MSFC S\&MA Concept Study Support

OExS Launch Vehicle Study July 21,2004

failure MTBF $=0.34$

11348 flights

with SRM Rel

999912

Cleaning solvents, (111.

Trichlorethane, Spirit 126 and Reveille) but No special protective

garments required; however. Handling major ordance devices (solid rocket motor) and Pyrotechnic

Poly Urethane-Foam application to ( 3$)$ stiffener rings, ETA ring and PR 855
Foam in ETA ring

$57 / 102$

$\%=1.76$ Thrust range is fixed $(100 /-50 \%)$ by $25 \% \quad 1.76$ design, not operationally controllable 2

Impulse range is fixed by design, no controllable

Safe \& arm device actuation during to control igniter assembly 


Criteria Discriminators
1. Closed Compartments/Confined
2. Number of Different Operating
Fluids Serviced:
3. Number of Ground Servicing
Interfaces:

4. Total Number of Tanks in the Architecture:

\section{Ref Technology RL10A-4 2.6.5.1.1 (Operational P\&W Engine)} Not Rocket Engine Focused

LH2, LO2, LHe, \& GHe

Preflight LHe conditioning/purge

LH2 \& LO2 Tanks, 2 High pressure GHe bottles (purge \& valve control). and TBD HP GHe bottles for Lox \& LH2 tank pressurization

LH2 tank \& feed-system, LO2 tank \& feed-system, 2 He pneumatic supply sys, LO2 tank GHe pressurization sys 5. Total Number of Vehicle Supplied LH2 tank GHe pressurization sys,GH2 Support Systems: autogenous bleed pressurization sys, TVC sys, 28volt power supply sys, data sys, Overboard vent sys (OVS), \& propellant utilization (PU) sys.

6. Total Number of Ground Interfactions Required:

7. Total Number of Separate 7lack of discipline functional integration):

8. Number of Separate Electrical/Electronic Interfaces:

\section{Number of Mechanical Element} Mating Operations:

LH2 \& LO2 leak check connections, turbopump torque meas Accessory Drive Pad, Chamber throat plug for pressure checks \& solenoid valve vent ports ( 4 valves)

Not Rocket Engine Focused Ignition system 28 volt DC power
supply (2), ignition system diagnostic (2), ignition system pressure switch valves ( 4 valves), \& 9 instrumentation

$$
\text { connectors. }
$$

Items in \#8 plus, (10) Mech: LH2 valve inlet, $L O 2$ valve inlet, Gimbleblock (2) TVC Actuators, interstage cooldown valve vent port/pump discharge cooldown valve vent port

Val

LO2 \& LH2 tanks, and $10 \mathrm{amb}, 8$ cold $\mathrm{He}$ bottles, and 1 combined $\mathrm{GH} / \mathrm{GHe}$ bottle

LH2 tank \& feed-system, LO2 tank \& feedsystem, He pneumatic supply sys, $\mathrm{GO}^{2}$ tank pressurization sys, GH2 tank

pressurization sys, POGO suppression sys, LH2 recirculation conditioning sys, LO2 bleed/He bubbling conditioning sys, Turbine spin-start system, APS Ullage control eng. sys (2) in support of propellant tank re-pressurization, solid rocket ullage control sys (2) in support of engine restart, Two 28volt power supply sys, Two 56 VDC inverter to 400 cycle AC power supply sys, Vehicle C\&C sys, TVC sys, Instrumentation interface sys, TPS heat shield, \& hazardous gas detection sys (2), FPHT, OPHT,FTIT, RPM, Solenoid (OVS), GHe bolcking purge line, GHe pneumatic control supply line, $\mathrm{GHe}$ engine chilldown supply line, \& propellant utilization valve.

\section{Source is the Design Ref.Doc. ICD's, e.g.,}

test ports, nozzle covers, inspection interface points.

Not Rocket Engine Focused

(6) electrical: (2) 5V/28V DC Power Bus, (2) Command, (2) Instrumentation Electrical Connectors

(13) Mech \& (6) Ele: $\mathrm{LH} 2 \& \mathrm{LO}_{2}$ feedlines, $\mathrm{LH} 2$ recirc.line, $\mathrm{GH} 2 \& \mathrm{GO}_{2}$ presslines, GHe Supply lines, LO2 sys GHe purge sys, TVC Hydraulic Supply \& Return lines,

1 Propellant valve actuator He Supply lines, Gimbleblock \& (2) TVC Actuators and (2)AC \& (2)DC power, (2) CommandData, a Command only, (4) Instrumentation

\begin{tabular}{|c|c|c|c|c|}
\hline Value & $\begin{array}{l}\text { Criteria } \\
\text { Factor }\end{array}$ & & Value & $\begin{array}{l}\text { Criteria } \\
\text { Factor }\end{array}$ \\
\hline N/A & & Not Rocket Engine Focused & N/A & \\
\hline 5 & 1.25 & LH2, LO2, \& GHe & 3 & 0.75 \\
\hline 2 & 2 & Preflight GHe purge & 1 & 1 \\
\hline 22 & 3.67 & LH2, LO2, $2 \mathrm{GHe}$ & 4 & 0.67 \\
\hline 20 & 1.67 & $\begin{array}{l}\text { LH2 sys, LOX sys, GHe sys, LH2 } \\
\text { repress sys, GOX repress sys, } \\
\text { Overboard vent sys (OVS), (2) } 28 \text { volt } \\
\text { electrical sys, data sys. }\end{array}$ & 9 & 0.75 \\
\hline
\end{tabular}

LH2 \& LO2 leak check connections, (2) turbopump torque measurement, (4) Chamber throat plug for pressure checks

Not Rocket Engine/Motor Focused N/A

(2) primary power connectors \& 0.26 valve control and (2) Instrumentation connectors

19. 4 electrical connectors and 4 aHical, LO2 \& LH2 feed 4 
11. Number of Safety Driven Limited (n)

12. Number of Commodities use that Require Medical Support Operations or Routine Training: 13. Total Number of Active

14. Number of Safety Driven Safety Functional Requirements to Maintain Safe Control of System during Flight and Ground Operations:

15. Number of Critical - 1 (Crit-1) System Functional Failure Modes: Gathering Devices:

17. Number of Maintenance Actions Planned Between Missions: Expendable, however, Reduce HP and safe ordance sys.

Engine Handling, blowdown \& EMA functional tests (Inert Purging), Pressurizing pneumatic bottles to flight values and connecting pyrotechnics

Working with inert gases, in confined spaces, pyrotechnics, and with cryogenics requires special training

Fuel inlet shutoff valve, oxidizer inle shutoff valve, integrated turbopump (fuel pump, oxidizer pump, turbine, \& gearbox), interstage cooldown valve, pump discharge cooldown valve, rast controlvalve, main fuel shutof valve, oxldzer how controlvalve. chilldown pyrovalves (2), and TVC gimbal actuators (2)

Gearbox, fuel pump, oxidizer pump, interpropellant seal pack, main fue shutoff valve vent cavity, thrust GHe vent cavity, inis. oxidzer GHe vent cavity, injector face,

oxidizer flow control value PU valve purges. These (blocking) purges are purges. These (blocking) purges are space where an atmosphere has enough relative humidity to facilitate H2O aspiration from the cryo-pumping caused by the chilled and pre-chilled hardware. Done by ground systems while on Pad and then by on-board purge lank. Not required for ascent

Source is the Design Ref. For Crit 1 \& $1 R$ Hardware items

1 pressure, 1 temps, \& 1 speed senso

Source is the Design Ref.Doc. Of Operations and Maintenance Requirements Specification (OMRS) ground test suggest nine; however, as engine has been restated 7 ime in space but requires the pyrotechnics space, but
High pressure bottles ( $\mathrm{GHe} \& \mathrm{GH} 2$ ) must be vented to $50 \%$ level before personne

Engine Handling, Inert Purging, 作

Working with inert gases, in confined spaces, and with cryogenics requires special training.

Main fuel valve, Main Lox valve, (2) ASI Lox Supply valve, Gas generator lox supply valve, Gas generator fuel supply valve, Gas generator Oxidizer purge valve, $\mathrm{GH}$ purge valve, Lox dome purge valve, Fuel He purge valve, High pressure theltrubopump, Pneu valve controls

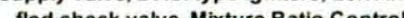
valves, (2) TVC gimbal actuators, 8 propellant valve solenoids and 5 check

Haz gas system, engine cryo conditioning S purge, barrier purges, pre-sta purges, MECO purge $\&$ P
suppression sys 18 propellant flow control and bleed valve sensors, \& 4 igniter sensors Instrumentation

$$
\text { valves }
$$

Reduce HP GHe bottles to $50 \%$ flight pressure

Engine Handling, blowdown \& EMA functional tests (Inert Purging), flight values

Working with inert gases, in confined spaces, and with cryogenics colant supply valve, Fuel coolant syste valve, Oxidizer Turbine Bypass value, (2) fuel \& Lox flowmeters, (2) fuel \& Lox bleed

12 Temperature, 16 Pressure, 2 Flow-rate, 
Source is the Problem Reporting and 18. Number of Maintenance Actions Corrective Action (PRACA) \& Planning Unplanned Between Missions:

and Scheduling

N/A - expendablo

gine: however,

qualicationtost

suggests 0 actions

Source is the Design Ref.Doc. Of

Operations and Maintenance

Requirements Specification (OMRS)

19. Expected Operational Lifetime - N/A - expendable engine; however, Firings:

ground test demonstrated 19 engine operations@ 920 sec. QUAL: 27 firings @ 3480 sec ea.

Source is the Design Ref.Doc. Of Operations and Maintenance Requirements Specification (OMRS)

N/A - expendable engine; howrs).

20. Expected Reusability-Number of Firings Before Over-Haul:

. firings 1810 soc on. Also: 2 flight Opertion 27020 . firings (2) 3400 soc ea. Earth Shelf Life: 10 years

21. Expected Reusability $1 \% \mathrm{HM}$ Replaced per Firing):

Source is the Problem Reporting and Corrective Action (PRACA) \& Plannin and Scheduling Sys (CAPSS) As-run

None (0) for flight qualified engine per s $19 \& 20$ above

$$
\text { Data }
$$

27 Starts

27 Starts firings @ 1810 sec ea.Also: 2 flight

$T B D$, but see no turnaround maintenance necessary

TBD

$\begin{array}{ll}\text { secs } & \text { starts/37 } \\ & 50 \text { starts \& } 2250\end{array}$

0.9

TBD

secs

30

50 secs

0.9

None (0)

for fligh

Source is the Problem Reporting and qualified

Corretive Action (PRACA) \& Planning engine

and Scheduling Sys (CAPSS) As-run Dat

per

items 19

N/A - expendable

engine; however

ground test

demonstrated 19

Source is the Design Ref.Doc. Of Operations and Maintenance

22. Expected Operational Lifetime

engine firings @ 1810 sec ea. Also: 2 920 sec. QUAL: 27 firings@ 3480 sec firings@3480 sec 10 years

Source is the Problem Reporting and Corrective Action (PRACA) \& Operations and Maintenance (MTBF):

N/A expendable But: QUAL: 27 firings@ 3480 sec

ea.

Cleaning solvents, but No special protective garments required; however, Pyrotechnic valves

24. Minimize the Number of Hazardous Fluids and Materials Used:

$$
\text { toxic }
$$

Actual Demonstrated: 111 starts $820,000 \quad 111$

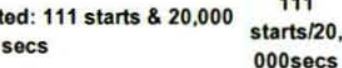

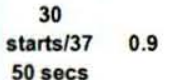

25. Avoid the Use of Toxic Fluids Cleaning solvents, but not considered 
26. Provide Propulsive Sys. That Accomodate a Large Thrust Range:
Thrust variability for a "fixed"

hardware design is tailored using Mixture ratio and fuel control for the expander cycle RL10A-4 or RL10B-2.

The RL10E with Electro-mechanical (EMA) controls for two valves

permitted a thrust range from $50-100 \% \quad 50-100 \%$ or a delta

without flowpath changes. The

RL10A-5 had the EMA's and some

flowpath changes for the fuel-side to

handle additional bypass flow around

the turbine and was able to create a 33

$100 \%$ variability range. Expander

cycle is very flexible in variability.

27. Provide Propulsive Sys. Tha

Accomodate a Large Impulse

Control Range with Focus on the

Minimum Impluse Side:

\section{see items $26 \& 28$}

\section{TBD need value}

from Russ J

Not ETO Rocket Engine Focused

N/A
N/A

$10-100 \%$ or $90 \%$ range

$90 \%$

RL10E derivative of RL10A engine with electronic controls demonstrated start to min-thrust, power level check and also had a $50 \%$ throttle to maximum delivered impulse

28. Provide Automated Hardware Corrective Action Capability capability. The control system design appraoch has matured to the level that prognostication as well as diagnostics for hardware corrective action can be performed with an upgrade to an

$$
\text { electronic control. }
$$

$T B D$ 


\section{Summary Evaluation Product Results and Conclusions}

It can be seen from the tables that follow, that 6 of the 7 candidate technologies evaluated would have an improved operational difficulty factor if matured and had a good chance of being better than the referenced technology for ETO WBS 2.6.1.

The operational reliability factor evaluations could be improved for 7 of the 7 candidate technologies being considered. It is also seen that 5 of the 8 mature candidates showed an improved operational reliability factor over the reference technology for ETO WBS 2.6.1. This assessment indicates that there is room for improving the operational reliability factors using the operational functional criteria discriminators as a guide.

While reviewing the table below for the WBS 2.6.5 In-space propulsion technologies, it can be seen that 6 of the 7 candidate technologies would show an improved operational difficulty factor over the reference case if matured.

The operational reliability factor evaluations could be improved for 7 of the 7 candidate technologies being considered. It is also seen that 3 of the 6 mature candidates showed an improved operational reliability factor over the reference technology for Inspace WBS 2.6.5. Again this assessment indicates that there is room for improving the operational reliability factors using the operational functional criteria discriminators as a guide.

In summary this evaluation tool can be used effectively in planning an R \& D program for improving the operational reliability and its effectiveness for improved safety as well as increasing the operability of these propulsion candidates. This product or its process should be used in achieving the objectives of affordability, supportability, and sustainability of future space transportation systems by improving their propulsion architectures. 
Evaluation Product Results for 2.6.1 ETO Chemical Propulsion System

\begin{tabular}{|c|c|c|c|c|c|c|c|c|c|c|c|c|c|c|c|c|c|}
\hline $\begin{array}{l}\text { Criteria Discriminators } \\
\text { ROLL-UP CRITERIA } \\
\text { VALUE SELECTED: }\end{array}$ & 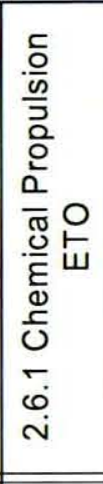 & 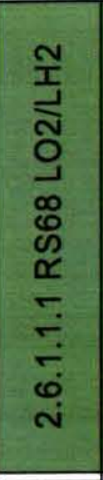 & 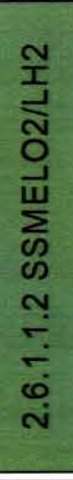 & 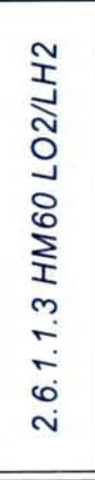 & 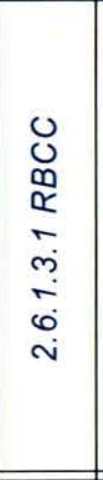 & 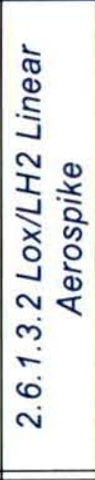 & 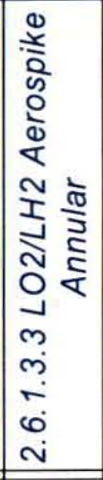 & 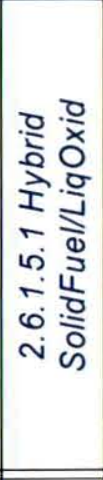 & 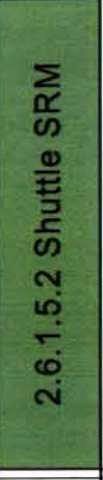 & 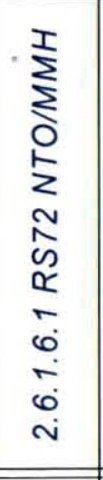 & 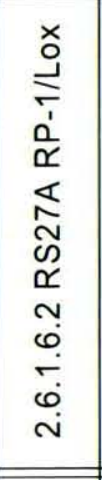 & 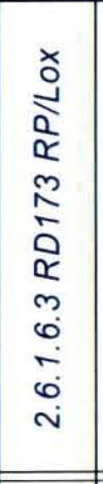 & 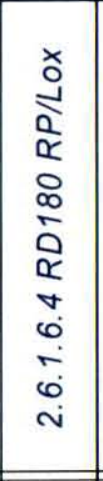 & 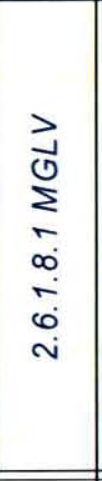 & 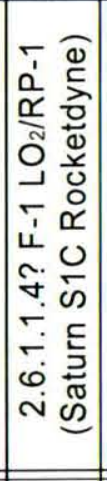 & 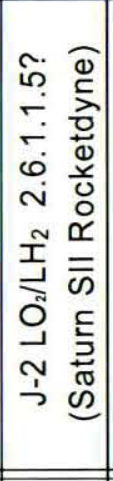 & 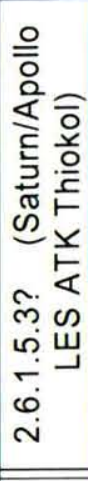 \\
\hline $\begin{array}{l}\text { Provide a well documented } \\
\text { operations definition (discriminator } \\
\text { criteria data) for evaluation and } \\
\text { understanding }\end{array}$ & & 1 & 1 & 9 & 9 & 9 & 9 & 9 & 1 & 3 & 1 & 3 & 3 & 9 & 1 & 1 & 1 \\
\hline$\frac{\text { Operational Difficulty Factor }}{\text { Criteria Column Total Value }}$ & & 34.88 & 27 & 22.8 & 33.01 & 28.93 & 27.19 & 32.73 & 76.35 & 49.78 & 43.6 & 44.25 & 37.27 & 25.1 & 50.4 & 27.04 & 17.57 \\
\hline $\begin{array}{l}\text { Operational Difficulty Factor } \\
\text { Criteria Column Normalized Value } \\
\text { (These Normalized Values are to } \\
\text { be transfered to the ATLAS TTB) }\end{array}$ & & 1.66 & 1 & 2.53 & 1.5 & 1.61 & 1.6 & 2.52 & 3.18 & 2.37 & 2.08 & 2.21 & 2.19 & 1.93 & 2.65 & 1.35 & 1.03 \\
\hline $\begin{array}{l}\text { Provide a well documented } \\
\text { operations definition (discriminator } \\
\text { criteria data) for evaluation and } \\
\text { understanding }\end{array}$ & & 1 & 1 & 9 & 9 & 9 & 9 & 9 & 1 & 3 & 1 & 1 & 1 & 9 & 1 & 1 & 1 \\
\hline $\begin{array}{l}\text { Operational Reliability Factor } \\
\text { Criteria Column Total Value }\end{array}$ & & 25.05 & 27 & 22.75 & 31.01 & 26.93 & 25.19 & 32.73 & 48.35 & 19.78 & 24.17 & 24.25 & 17.27 & 23.12 & 32.4 & 27.04 & 8.57 \\
\hline $\begin{array}{l}\text { Operational Reliability Factor } \\
\text { Criteria Column Normalized Value } \\
\text { (These Normalized Values are to } \\
\text { be transfered to the ATLAS TTB) }\end{array}$ & & 1.25 & 1 & 2.53 & 1.55 & 1.68 & 1.68 & 2.52 & 2.1 & 1.1 & 1.21 & 1.28 & 1.08 & 2.1 & 1.71 & 1.35 & 0.5 \\
\hline
\end{tabular}


Evaluation Product Results for 2.6.5 In-Space Chemical Propulsion System

\begin{tabular}{|c|c|c|c|c|c|c|c|c|c|c|c|c|c|c|c|}
\hline $\begin{array}{c}\text { Criteria Discriminators } \\
\text { ROLL-UP CRITERIA } \\
\text { VALUE SELECTED: }\end{array}$ & 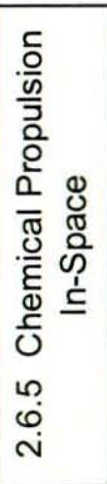 & 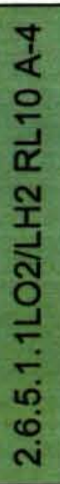 & 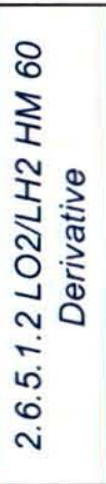 & 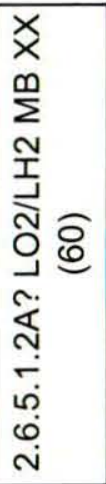 & 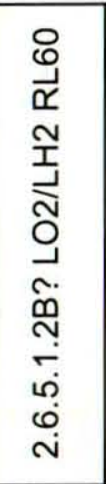 & 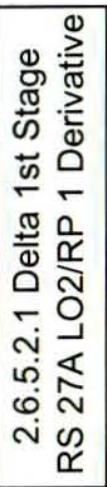 & 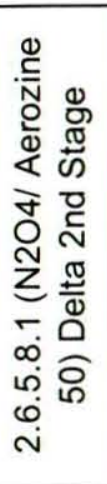 & 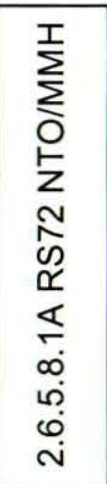 & 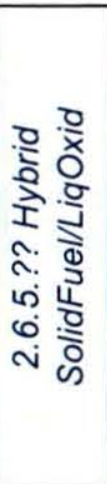 & 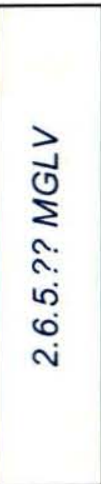 & 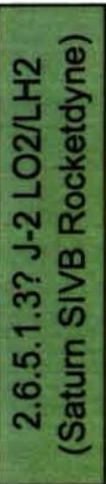 & 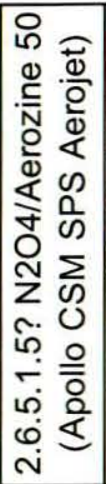 & 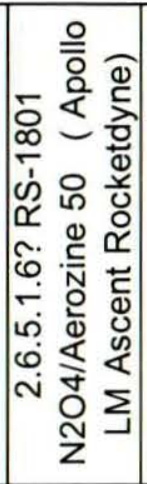 & 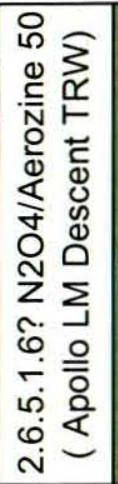 & 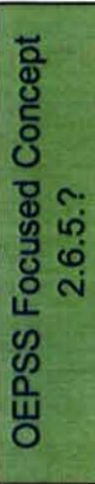 \\
\hline $\begin{array}{l}\text { Provide a well documented } \\
\text { operations definition (discriminator } \\
\text { criteria data) for evaluation and } \\
\text { understanding }\end{array}$ & & 1 & 9 & 3 & 3 & 1 & 1 & 3 & 9 & 9 & 1 & 1 & 1 & 1 & 9 \\
\hline$\frac{\text { Operational Difficulty Factor }}{\text { Criteria Column Total Value }}$ & & 27 & 19.36 & 23.4 & 20.6 & 47.01 & 42.86 & 35.44 & 22.62 & 28.73 & 30.84 & 25.76 & 27.89 & 28.27 & 21.43 \\
\hline $\begin{array}{l}\text { Operational Difficulty Factor } \\
\text { Criteria Column Normalized Value } \\
\text { (These Normalized Values are to } \\
\text { be transfered to the ATLAS TTB) }\end{array}$ & & 1 & 1.94 & 1.11 & 1.08 & 2.35 & 2.04 & 1.77 & 1.89 & 2.39 & 1.54 & 1.29 & 1.33 & 1.57 & 1.07 \\
\hline $\begin{array}{l}\text { Provide a well documented } \\
\text { operations definition (discriminator } \\
\text { criteria data) for evaluation and } \\
\text { understanding }\end{array}$ & & 1 & 9 & 3 & 3 & 1 & 1 & 3 & 9 & 9 & 1 & 1 & 1 & 1 & 9 \\
\hline$\frac{\text { Operational Reliability Factor }}{\text { Criteria Column Total Value }}$ & & 27 & 22.36 & 21.15 & 18.78 & 40.51 & 30.53 & 23.19 & 22.54 & 27.3 & 31.66 & 15.43 & 16.64 & 17.02 & 22.33 \\
\hline $\begin{array}{l}\text { Operational Reliability Factor } \\
\text { Criteria Column Normalized Value } \\
\text { (These Normalized Values are to } \\
\text { be transfered to the ATLAS TTB) }\end{array}$ & & 1 & 1.86 & 1.11 & 0.99 & 1.93 & 1.61 & 1.29 & 1.88 & 2.73 & 1.58 & 0.77 & 0.79 & 0.95 & 1.12 \\
\hline
\end{tabular}


The objective of developing a TTB for the ATLAS for the two WBSs of 2.6.1 and 2.6.5 for chemical propulsion was achieved. The following overall assessment of this project is included below.

OPERATIONAL METRICS DEVELOPMENT / DETERMINATION for ATLAS-TTB Major observations from process

- Operational improvements aren't always technology constrained, but often driven by design choices - Apollo / Saturn vs. Current

- Traditional process of optimizing for minimum weight at the subsystem, system or contractual element level does not provide overall Space Transportation system for lowest LCC, Highest Reliability or Highest Safety.

- Traditional process was developed for achievement of maximum performance, e.g.,

- "Design Definition Process" needed to achieve Affordable, Sustainable Transportation System must be focus/optimized on major objectives of Lowest LCC, High Dependability, High Operability, and Maximum Mission Assurance/Safety - Followed by performance assessment \& adjustment to achieve closure if required.

- Requirements must be defined around the major objectives above

- Must maintain focus on these above objectives throughout the entire design and operations phases

\section{If you do what you have always done, you will get what you got before. Conceptual definition process must be changed.}

\section{- The requirement of "SUSTAINABLE EXPLORATION" must be enforced}

\section{Acknowledgment}

The SPST is a national volunteer organization of government, industry, and university experts in space propulsion and propulsion-related technologies. The SPST is unique in its organization, membership and capability. It was chartered in 1991 by NASA and has a diversified membership of retired and active senior engineers, managers and scientist from industry, government and academia who have a wealth of hardware experience. The SPST was, and continues to be, dedicated to the development and operation of safe, dependable, affordable and sustainable space transportation systems. This is generally believed to be the key element in the Nation's ability to meet the goals of a Space Exploration Program. SPST WEB SITE LINK: http://spst.services.officelive.com/default.aspx 